\title{
Influence of Shielding Gas on Fume Size Morphology and Particle Composition for Gas Metal Arc Welding
}

\author{
Kristin R. CARPENTER, ${ }^{1)}$ Brian J. MONAGHAN ${ }^{2)}$ and John NORRISH ${ }^{11}$ \\ 1) Welding Engineering Research Group, University of Wollongong, Wollongong, NSW, 2522, Australia. \\ E-mail: Kristin.carpenter@bluescopesteel.com, john_norrish@uow.edu.au \\ 2) School of Mechanical Materials and Mechatronics Engineering and BlueScope Steel Metallurgy Centre, University of \\ Wollongong, Wollongong, NSW, 2522, Australia. E-mail: monaghan@uow.edu.au
}

(Received on April 30, 2008; accepted on August 4, 2008)

\begin{abstract}
Shielding gas is an important parameter in Gas Metal Arc Welding (GMAW). Nevertheless, the influence of shielding gas on particle composition and size distribution of welding aerosols is not clearly understood. Increasing the $\mathrm{O}_{2}$ or $\mathrm{CO}_{2}$ content of Ar-based shielding gases resulted in an increase in the average particle size. For binary and ternary $\mathrm{Ar}, \mathrm{CO}_{2}, \mathrm{O}_{2}$ mixtures, increasing $\mathrm{CO}_{2}$ had a greater impact than raising $\mathrm{O}_{2}$ on particle size. Variations in $\mathrm{Ar}-\mathrm{He}-\mathrm{CO}_{2}$ mixtures had the least influence. For $100 \% \mathrm{CO}_{2}$, the particle size distribution was altered significantly due to the change of the weld transfer mode to globular and particle size coarsened with increasing arc voltage. Shielding gas composition had no observable influence on particle composition and only a slight variation of composition with particle size was observed. Particles were identified as $(\mathrm{Fe}, \mathrm{Mn})_{3} \mathrm{O}_{4}$ with trace additions of $\mathrm{Si}$.
\end{abstract}

KEY WORDS: shielding gas; fume; GMAW; particle size, TEM.

\section{Introduction}

Welding fumes generated during gas metal arc welding (GMAW) process are potentially hazardous to the welder's health. Welding aerosols consist of metal oxide particles that can remain suspended in the air and thus, inhaled by welders. ${ }^{1-3)}$ The chemical composition, particle size and the amount of the fume particulates are important parameters in determining the toxicity of welding aerosols. ${ }^{3,4)}$

The amount and composition of the fume from GMAW depends on the welding parameters, the filler and base materials and the shielding gas. ${ }^{5-7)}$ This paper will address the influence of the shielding gas on the chemical composition and particle size morphology of welding aerosols generated by robotic GMAW.

Due to the high temperatures involved with the welding arc, metal vapours are thought to predominately originate from the molten top of the welding electrode, ${ }^{8)}$ though the molten weld pool is also a significant source. ${ }^{1,6)}$ Metal vapours are readily oxidised, rapidly condensing into nanoparticles. These particles can then grow though time is limited due to rapid cooling resulting from the plasma jet and shielding gas flow sweeping the particles away from the hot arc. Zimmer ${ }^{9)}$ suggests that particle growth due to coagulation, the collision of liquid or solid particles, will compete with condensation, particle growth due to additional metal vapours.

The influence of the proportion of reactive components in the shielding gas, $\mathrm{CO}_{2}$ and $\mathrm{O}_{2}$, on particle size distribution is not widely understood. The ability of particles to be inhaled and the resultant biological effects is dependant, to a large degree, on particle size. There is no agreement on how much inhaled fume remains in the lungs. The Australian standards ${ }^{10)}$ reports that $100 \%$ of air borne particles at $1 \mu \mathrm{m}$ or less will penetrate to the unciliated airways. Welding fume is predominately less than $1 \mu \mathrm{m} .^{6,11)}$ Jenkins and Eagar ${ }^{11)}$ indicates that particles between 0.1 and $1 \mu \mathrm{m}$ can be exhaled, resulting in approximately $30 \%$ of particles in this size range depositing in the lungs. Particles less than $0.1 \mu \mathrm{m}$ are deposited into the lungs. Voitkevich ${ }^{3)}$ suggests approximately $80 \%$ of particles less than $0.1 \mu \mathrm{m}$ will be exhaled. Friedlander ${ }^{12)}$ reported that the deposition of spherical particles of a given density in the lung is a function of particle size and varies from individual to individual. Particles between 0.1 to $1 \mu \mathrm{m}$ have the lowest fraction deposited in to the lungs (30-40\%) and for particles $<0.1 \mu \mathrm{m}$, the fraction deposited increased exponentially. Pires ${ }^{13,14)}$ claims that it is not the particle size but the size of particle agglomerations that is the defining parameter. Clearly, there are discrepancies in the literature regarding the exact interaction of particles of a particular size with the respiratory system, but it is evident that particle size is a critical factor.

Particle size distributions of welding aerosols are often determined using advanced analytical techniques. Sowards ${ }^{15}$ ) used an electrical low pressure cascade impactor (ELPI) to determine particle size distribution, where the lower limit of the impactor was $30 \mathrm{~nm}$. Cascade impactors utilise the principle of particle inertia and aerodynamic diameter to separate particles. The cut-off diameter for each stage of the cascade impactor, in the experiments by Sowards, ${ }^{15)}$ was 
reported to have $50 \%$ efficiency. Work by Zimmer $9,16,17)$ used an electrostatic classifier, scanning mobility particle sizer (SMPS), with a condensation particle counter (CPC) that was configured to measure particles down to $4.53 \mathrm{~nm}$. When collecting a representative sample using sampling tubes, potential problems include; preferential withdrawal of particles with respect to size and deposition of particles inside the tube. ${ }^{12)}$ Electrostatic classifiers establish a charge on entering particles, which are then separated according to their electrical mobility. Zimmer and Biswas ${ }^{17)}$ found that particle counting efficiency decreased with decreasing particle size. This was attributed to smaller particles being scavenged by larger particles.

In this study welding fume particle size distributions were determined using TEM and an image analysis technique. This technique is capable of distinguishing agglomerated particles and accurately counting fume particles down to $3-4 \mathrm{~nm}$ in size.

\section{Experimental Procedures}

GMAW was carried out with a Cigweld Trans Robot WS-0550 linked to a Fronius Trans Synergic 4000 power supply and wire feed system. The welding parameters, nominal chemical composition of the base plate, welding wire and shielding gases are listed in Table 1. Welding was generally carried out in spray transfer mode although this changed to globular mode when using $100 \% \mathrm{CO}_{2}$ gas. For $100 \% \mathrm{CO}_{2}$, three voltages were used, $32 \mathrm{~V}, 34 \mathrm{~V}$ and $36 \mathrm{~V}$, to investigate the effect of increasing arc voltage on particle size.

A WITT KM 30-4 gas mixer was used to generate the shielding gas mixtures listed in Table 1. A Platon flowmeter was placed between the gas mixer and welding machine to ensure a constant flow-rate. The flow meter was calibrated with air using a water displacement test, where the flow rate was calculated by measuring the time taken for a given volume of water to be displaced by the gas. The flow meter reading was then adjusted for the selected gas composition using gas density corrections and Eq. (1).

$$
F_{\text {gas }}=\frac{F_{\text {air }}}{k}, \quad k=\sqrt{r}
$$

Where $F_{\text {gas }}$ is the flow rate of the selected gas, $F_{\text {air }}$ is the flow rate for air and $k$ is a constant based on the relative gas density to air, $r$, at constant temperature and pressure. The values used for, $r$, were; $\mathrm{Ar} 1.380, \mathrm{CO}_{2} 1.520$, He 0.138 and $\mathrm{O}_{2} 1.105$ and ideal gas-mixing was assumed to calculate the density for each gas mixture.

A $255 \mathrm{~mm}$ long bead was welded onto the plain carbon steel plate in a fume box and fume for TEM analysis was collected on an Aluminium SEM stub. The stub was in a fixed position $30 \mathrm{~mm}$ from the centre line of the arc in the welding direction and $50 \mathrm{~mm}$ above the plate, as depicted in Fig. 1. This position, determined from previous work, ${ }^{18)}$ was chosen to provide sufficient fume collection for TEM analysis. Chemical analysis was performed with TEMEDS, using a Jeol, JEM 2011 at $200 \mathrm{kV}$, equipped with a $\mathrm{Si}(\mathrm{Li})$ detector and using a double tilt beryllium holder. Fume particles were washed off the stub by ultrasonic agi-
Table 1. Welding parameters and shielding gas mixtures used for robotic GMAW.

\begin{tabular}{|l|l|l|}
\hline Weld process & GMAW, spray transfer & Shielding gas mixtures \\
\hline Material and & $\begin{array}{l}10 \mathrm{~mm} \text { thick mild steel plate } \\
\text { composition }\end{array}$ & $\mathrm{Ar}+5 \% \mathrm{O}_{2}$ \\
\cline { 3 - 3 } & $(0.22 \% \mathrm{C}, 1.6 \% \mathrm{Mn}, 0.55 \% \mathrm{Si})$ & $\mathrm{Ar}+5 \% \mathrm{CO}_{2}$ \\
\hline Plate condition & Ground and cleaned with ethanal & $\mathrm{Ar}+10 \% \mathrm{CO}_{2}$ \\
\hline Wire & AWS A5.18 (ER70S-6) uncoated, & $\mathrm{Ar}+18 \% \mathrm{CO}_{2}$ \\
\cline { 3 - 3 } & $1.2 \mathrm{~mm}$ diameter & $\mathrm{Ar}+5 \% \mathrm{CO}_{2}+2 \% \mathrm{O}_{2}$ \\
\hline Wire composition & $0.08 \% \mathrm{C}, 1.16 \% \mathrm{Mn}, 0.7 \% \mathrm{Si}$ & $\mathrm{Ar}+12 \% \mathrm{CO}_{2}+2 \% \mathrm{O}_{2}$ \\
\hline Gas flow rate & $20 \mathrm{~L} \mathrm{~min}{ }^{-1}$ & $\mathrm{Ar}+18 \% \mathrm{CO}_{2}+2 \% \mathrm{O}_{2}$ \\
\hline Wire feed rate & $8 \mathrm{~m} \mathrm{~min}-1$ & $\mathrm{Ar}+5 \% \mathrm{CO}_{2}+5 \% \mathrm{O}_{2}$ \\
\hline Voltage & $32 \mathrm{volts}$ & $\mathrm{Ar}+12 \% \mathrm{CO}_{2}+4 \% \mathrm{O}_{2}$ \\
\hline CTWD & $20 \mathrm{~mm}^{-1}$ & $\mathrm{Ar}+20 \% \mathrm{He}^{2}+12 \% \mathrm{CO}_{2}$ \\
\hline Polarity & $\mathrm{DC}+$ & $\mathrm{Ar}+30 \% \mathrm{He}^{2}+6 \% \mathrm{CO}_{2}$ \\
\hline Weld travel speed & $300 \mathrm{~mm} \mathrm{~min}^{-1}$ & $100 \% \mathrm{CO}_{2}$ \\
\hline & & \\
\hline
\end{tabular}

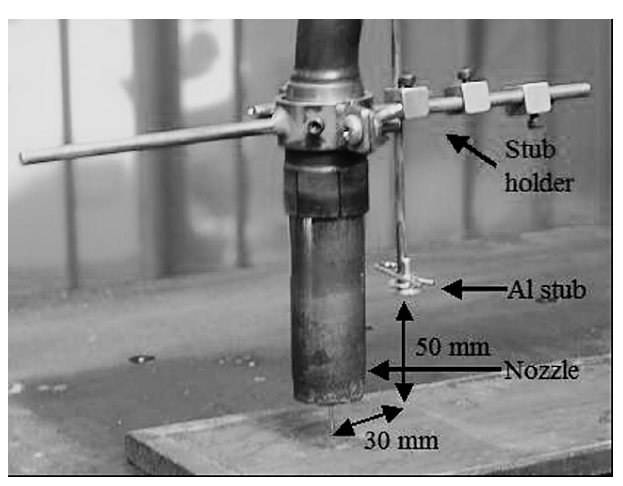

Fig. 1. Set-up of the Al SEM stub on the welding torch nozzle for fume collection.

tation into a bath of ethanol, where the ethanol was pre-filtered through $0.22 \mu \mathrm{m}$ micro-pore filter to remove contaminates. This mixture was then deposited onto holey carboncoated TEM copper grids. Any micro-spatter that washed off the stub sunk to the bottom of the ethanol bath and as a result was excluded from analysis. TEM images of particulate fume were taken at $200 \mathrm{Kx}$ magnification and were measured using Scion Image software to generate particle size distribution curves. For each experiment approximately 1500 particles were counted.

A GBC Scientific Equipment, MMA X-ray diffractometer was used to identify bulk phases in the fume. Fume was transferred onto a low-background quartz slide, where a thin layer of petroleum jelly was used to adhere the fume to the slide. Scans were conducted from $15^{\circ}$ to $75^{\circ} 2 \theta$ at a rate of $1^{\circ} \mathrm{min}^{-1}$, step size 0.02 and with the X-ray source running at $1.0 \mathrm{~kW}(35 \mathrm{kV}$ and $28.8 \mathrm{~mA})$.

\section{Results}

\subsection{XRD}

XRD analysis of the (bulk) fume identified the $\mathrm{Fe}_{3} \mathrm{O}_{4^{-}}$ spinel type phase (Magnetite-index card 011-0614 ICDD data base). There was no evidence that shielding gas com- 
position affected the composition of the bulk fume. There was a slight peak shift that indicated that small levels of $\mathrm{Mn}$, as detected by TEM-EDS, substituted for $\mathrm{Fe}$ in the $\mathrm{Fe}_{3} \mathrm{O}_{4}$ phase. This is consistent with other studies reported in the literature. ${ }^{15,19)}$

\subsection{TEM-EDS}

The average compositions determined by TEM-EDS for a number of particles for each shielding gas mixture are in Table 2. The data for the variation of fume composition with particle size was taken from the $\mathrm{Ar}-\mathrm{CO}_{2}$ and $\mathrm{Ar}-$ $\mathrm{CO}_{2}-\mathrm{O}_{2}$ groups only; results are shown in Table $\mathbf{3}$ and are plotted in Fig. 2.

TEM-EDS identified fume particles as composed mainly of Fe-oxide $\left(\mathrm{Fe}_{3} \mathrm{O}_{4}\right)$ with small amounts of $\mathrm{Mn}$ and trace amounts of $\mathrm{Si}$. EDS results showed that small peaks of $\mathrm{Si}$ and $\mathrm{O}$ were present in the background when the electron beam was focused on the carbon film. It is likely that the trace amounts of $\mathrm{Si}$ and $\mathrm{O}$, about $0.2-0.5 \mathrm{wt} \%$, were at least in part from O-ring grease contamination from TEM sample holders. The presence of $\mathrm{Si}$ in fume particles is widely known but with the uncertainty of background contamination it is difficult to accurately determine the amount of $\mathrm{Si}$ in the fume particles. Results suggest that Si levels in the

Table 2. TEM-EDS composition analysis of fume particles for each shielding gas mixture.

\begin{tabular}{|c|c|c|c|c|c|}
\hline Shielding gas & $\mathrm{O}(w t \%)$ & Si(wt\%) & $M n(w t \%)$ & $\mathrm{Fe}(w t \%)$ & $\mathrm{Mn} / \mathrm{Fe}$ \\
\hline Ar- $-5 \% \mathrm{O}_{2}$ & 27.5 & 0.9 & 8.7 & 62.8 & 0.14 \\
\hline $\mathrm{Ar}-5 \% \mathrm{CO}_{2}$ & 27.5 & 0.7 & 7.0 & 64.8 & 0.11 \\
\hline $\mathrm{Ar}-10 \% \mathrm{CO}_{2}$ & 27.4 & 0.3 & 5.9 & 66.4 & 0.09 \\
\hline $\mathrm{Ar}-18 \% \mathrm{CO}_{2}$ & 28.1 & 1.3 & 4.2 & 66.3 & 0.06 \\
\hline $\mathrm{Ar}-5 \% \mathrm{CO}_{2}-2 \% \mathrm{O}_{2}$ & 27.5 & 0.6 & 7.4 & 64.5 & 0.12 \\
\hline $\mathrm{Ar}-12 \% \mathrm{CO}_{2}-2 \% \mathrm{O}_{2}$ & 27.8 & 1.0 & 5.8 & 65.3 & 0.09 \\
\hline $\mathrm{Ar}-18 \% \mathrm{CO}_{2}-2 \% \mathrm{O}_{2}$ & 28.4 & 2.3 & 7.0 & 62.3 & 0.12 \\
\hline $\mathrm{Ar}-5 \% \mathrm{CO}_{2}-5 \% \mathrm{O}_{2}$ & 28.1 & 1.6 & 6.1 & 64.2 & 0.10 \\
\hline $\mathrm{Ar}-12 \% \mathrm{CO}_{2}-4 \% \mathrm{O}_{2}$ & 28.1 & 1.6 & 6.1 & 64.2 & 0.10 \\
\hline $\mathrm{Ar}-20 \% \mathrm{He}-12 \% \mathrm{CO}_{2}$ & 28.1 & 1.3 & 4.0 & 66.6 & 0.06 \\
\hline Ar- $30 \% \mathrm{He}-6 \% \mathrm{CO}_{2}$ & 27.7 & 0.8 & 6.1 & 65.4 & 0.10 \\
\hline Ar-30\%He-10\%CO ${ }_{2}$ & 27.7 & 0.8 & 4.8 & 66.8 & 0.07 \\
\hline $100 \% \mathrm{CO}_{2}$ & 29.6 & 4.4 & 6.5 & 59.4 & 0.11 \\
\hline Average* $^{*}$ & 27.8 & 1.1 & 6.1 & 65.0 & 0.1 \\
\hline
\end{tabular}

${ }^{*}$ The $100 \% \mathrm{CO}_{2}$ data was not included in the average as they were from fume collected while welding in globular mode, not spray transfer.

Table 3. Particle composition as a function of particle size range for the $\mathrm{Ar}-\mathrm{CO}_{2}$ and $\mathrm{Ar}-\mathrm{CO}_{2}-\mathrm{O}_{2}$ shielding gas groups.

\begin{tabular}{|c|c|c|c|c|c|}
\hline Particle size range & $\mathrm{O}(\mathrm{wt} \%)$ & $\mathrm{Si}(\mathrm{wt} \%)$ & $\mathrm{Mn}(\mathrm{wt} \%)$ & $\mathrm{Fe}(\mathrm{wt} \%)$ & $\mathrm{Mn} / \mathrm{Fe}$ \\
\hline$<20 \mathrm{~nm}$ & 28.4 & 2.1 & 6.8 & 62.8 & 0.11 \\
\hline $21-40 \mathrm{~nm}$ & 28.3 & 2.1 & 6.7 & 62.9 & 0.11 \\
\hline $41-60 \mathrm{~nm}$ & 27.8 & 1.2 & 7.0 & 64.1 & 0.11 \\
\hline $61-80 \mathrm{~nm}$ & 27.6 & 0.7 & 6.4 & 65.3 & 0.10 \\
\hline$>81 \mathrm{~nm}$ & 27.5 & 0.4 & 5.4 & 66.8 & 0.08 \\
\hline
\end{tabular}

fume were similar to the wire composition; however, significant Mn enrichment of the fume was observed.

\subsection{Fume Morphology}

Typical bright-field TEM images taken at an accelerating voltage of $200 \mathrm{kV}$ are shown in Figs. 3 and 4. Figure 3 shows a mixture of spherical and faceted particles, including the tendency of the particles to agglomerate in groups and chain-like structures. In Fig. 4, lattice fringes are clearly visible indicating the crystalline structure of the fume particle. TEM observations yielded no evidence of metal core-oxide shelled particles in any condition, which have previously been reported in the literature. ${ }^{20)}$

\subsection{Fume Particle Size Distribution}

The repeatability of the particle analysis technique, for

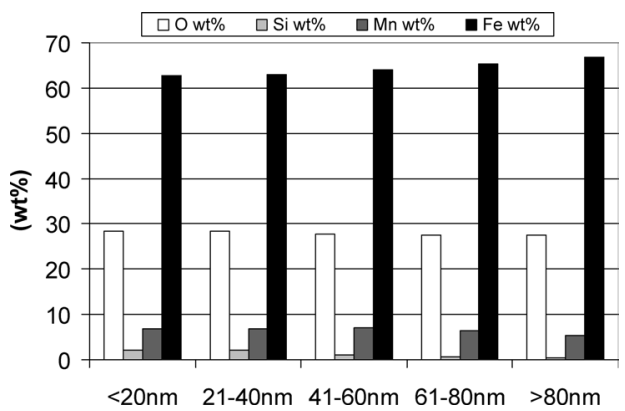

Fig. 2. Variation of particle composition with particle size range for the $\mathrm{Ar}-\mathrm{CO}_{2}$ and $\mathrm{Ar}-\mathrm{CO}_{2}-\mathrm{O}_{2}$ groups.

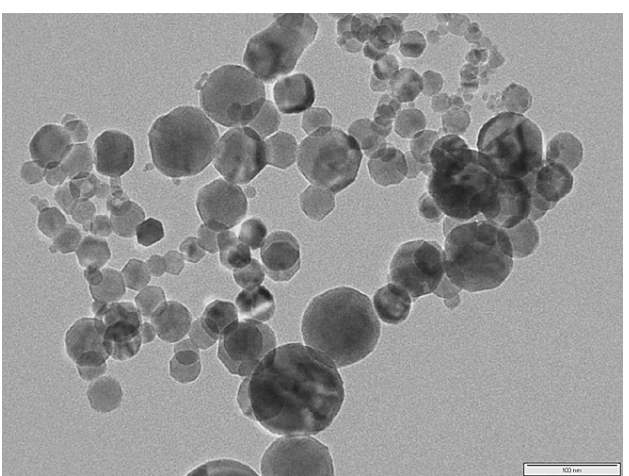

Fig. 3. Typical bright field TEM image taken at $200 \mathrm{Kx}$ showing a mixture of particle sizes with spherical and faceted morphology, often in chain-like structures $(100 \mathrm{~nm})$.

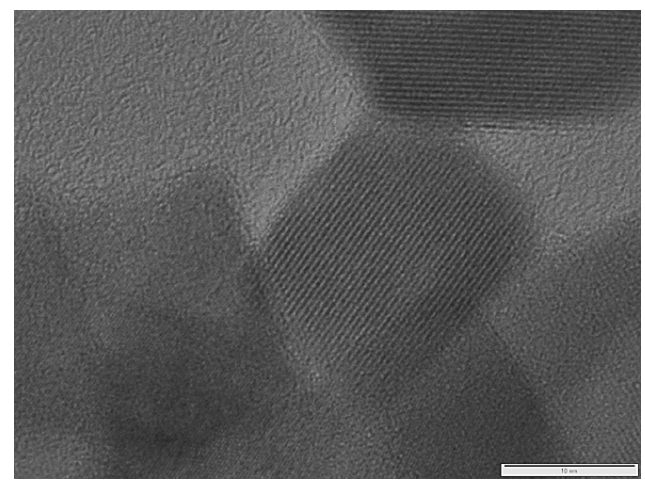

Fig. 4. Typical bright field high magnification TEM image of fume particles showing lattice fringes and a single crystal structure $(10 \mathrm{~nm})$ 


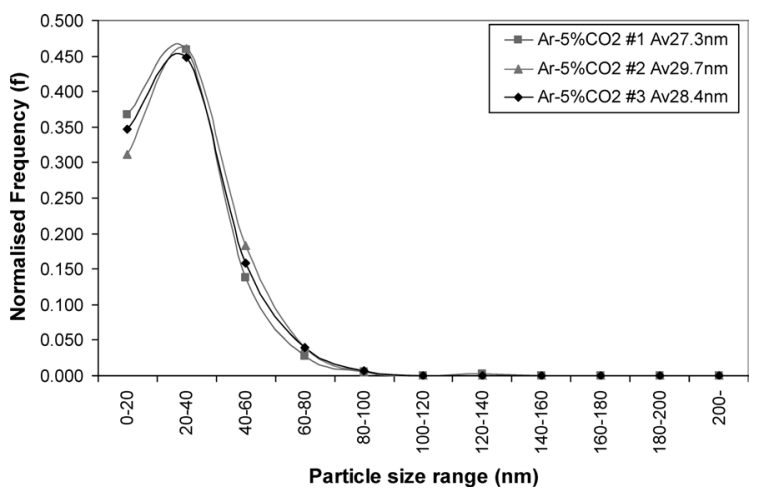

Fig. 5. Normalised frequency versus particle diameter for the $\mathrm{Ar}-5 \% \mathrm{CO}_{2}$ shielding gas showing the repeatability over three experiments.

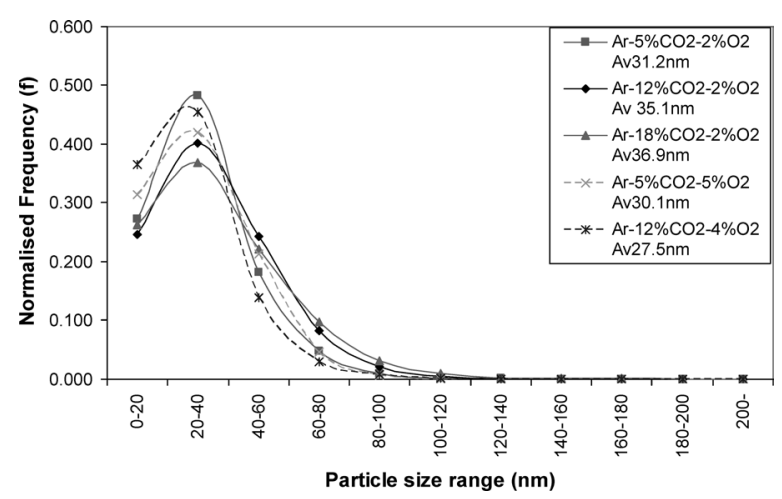

Fig. 6. Normalised frequency versus particle diameter for the $\mathrm{Ar}-\mathrm{CO}_{2}-\mathrm{O}_{2}$ shielding gas group.

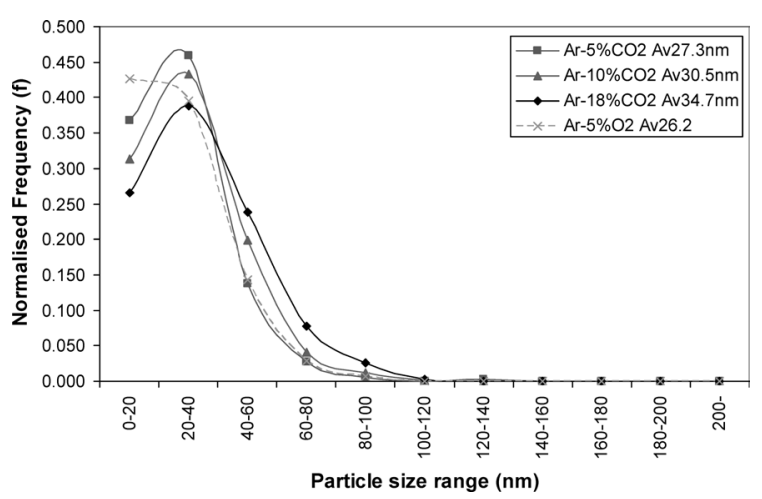

Fig. 7. Normalised frequency versus particle diameter for the $\mathrm{Ar}-\mathrm{CO}_{2}$ shielding gas group and $\mathrm{Ar}-5 \% \mathrm{O}_{2}$.

the $\mathrm{Ar}-5 \% \mathrm{CO}_{2}$ shielding gas, is displayed in Fig. 5. The three repeats closely followed the same trend and the greatest discrepancy was for the particle range of 0-20 nm. The percentage error for the average particle size, total percentage of fume $<40 \mathrm{~nm}$ and $<60 \mathrm{~nm}$ were $4.3 \%, 3.5 \%$ and $0.6 \%$, respectively. Fume particle size distributions are plotted as normalised frequency versus particle diameter and graphs for the $\mathrm{Ar}-\mathrm{CO}_{2}-\mathrm{O}_{2}$ group, $\mathrm{Ar}-\mathrm{CO}_{2}$ group, $\mathrm{Ar}-\mathrm{He}-$ $\mathrm{CO}_{2}$ group and for pure $\mathrm{CO}_{2}$ are shown in Figs. 6 to 9 , respectively.

In order to characterise the effects of shielding gas on particle size the total number of fume $<40 \mathrm{~nm}$ and $<60 \mathrm{~nm}$ (covering the bulk of the particle distribution) was used, as shown in Fig. 10. Table 4 summarises the average particle size, the total $<40 \mathrm{~nm}$ and the total $<60 \mathrm{~nm}$ for each shield-

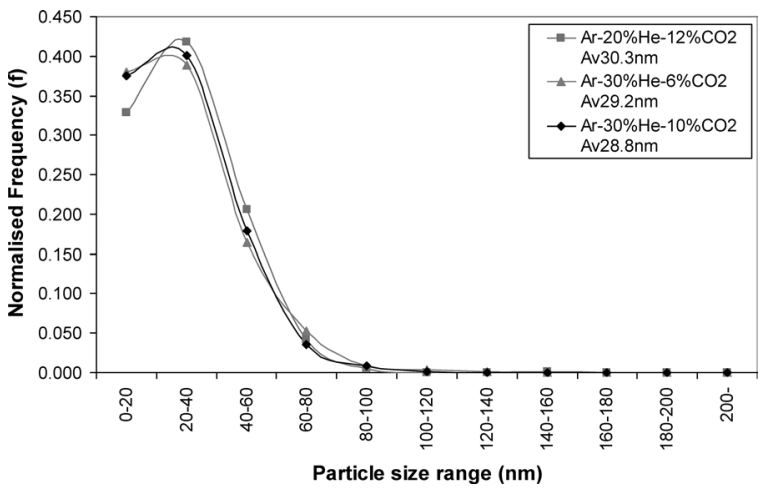

Fig. 8. Normalised frequency versus particle diameter for the $\mathrm{Ar}-\mathrm{He}-\mathrm{CO}_{2}$ shielding gas group.

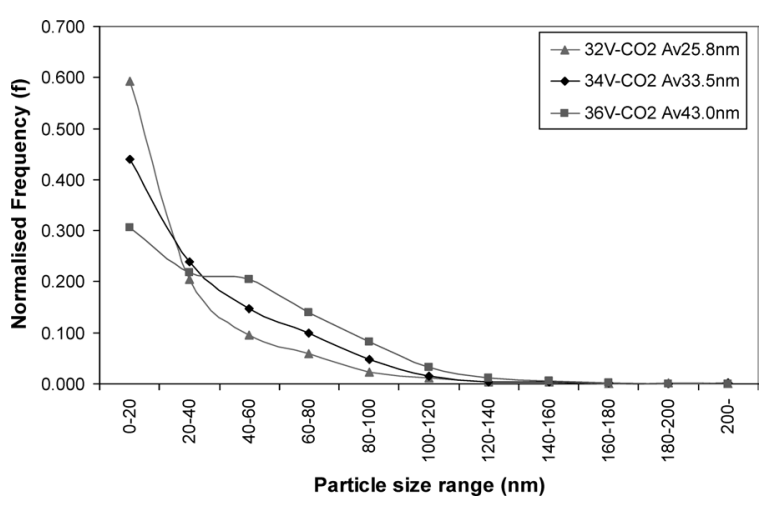

Fig. 9. Normalised frequency versus particle diameter for $100 \%$ $\mathrm{CO}_{2}$ shielding gas at $32 \mathrm{~V}, 34 \mathrm{~V}$ and $36 \mathrm{~V}$.

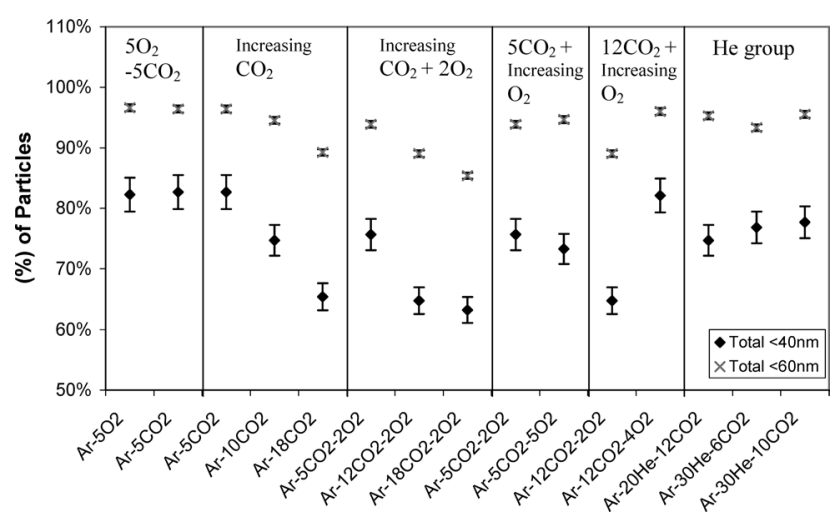

Fig. 10. Variation in total particles $<40 \mathrm{~nm}$ and $<60 \mathrm{~nm}$ for different groups of the shielding gas mixtures, with error bands included.

ing gas mixture.

\section{Discussion}

\subsection{Particle Size Distributions}

A clear trend of increasing average particle size with increasing $\mathrm{CO}_{2}$, as shown in Figs. 7 and 10. The entire Ar$\mathrm{CO}_{2}$ group showed similar particle distribution curves (Fig. 7) but there was a shift towards coarser particles at the expense of finer particles as $\% \mathrm{CO}_{2}$ increased. It should be noted that in Fig. 10 that the average particle size decreases as the percentage of particles value increases. The $\mathrm{Ar}-$ $5 \% \mathrm{CO}_{2}$ and the $\mathrm{Ar}-5 \% \mathrm{O}_{2}$ results showed similar average particle size and percentage of total fume $<40 \mathrm{~nm}$, but Fig. 
Table 4. Summary of average particle size, the total percentage of fume $<40 \mathrm{~nm}$ and $<60 \mathrm{~nm}$ for each shielding gas mixture.

\begin{tabular}{|c|c|c|c|c|}
\hline Gas composition & $\begin{array}{c}\text { Average } \\
(\mathrm{nm})\end{array}$ & $\begin{array}{c}\quad \text { Total } \\
<40 \mathrm{~nm}\end{array}$ & $\begin{array}{c}\text { Total } \\
<60 \mathrm{~nm}\end{array}$ & Total $^{*}$ \\
\hline $\mathrm{Ar}-5 \% \mathrm{O}_{2}$ & 26.2 & $82.3 \%$ & $96.6 \%$ & 1567 \\
\hline $\mathrm{Ar}-5 \% \mathrm{CO}_{2}$ & 27.3 & $82.7 \%$ & $96.4 \%$ & 1587 \\
\hline $\mathrm{Ar}-10 \% \mathrm{CO}_{2}$ & 30.5 & $74.7 \%$ & $94.5 \%$ & 1503 \\
\hline $\mathrm{Ar}-18 \% \mathrm{CO}_{2}$ & 34.7 & $65.4 \%$ & $89.2 \%$ & 1507 \\
\hline $\mathrm{Ar}-5 \% \mathrm{CO}_{2}-2 \% \mathrm{O}_{2}$ & 31.2 & $75.7 \%$ & $93.9 \%$ & 1409 \\
\hline $\mathrm{Ar}-12 \% \mathrm{CO}_{2}-2 \% \mathrm{O}_{2}$ & 35.1 & $64.8 \%$ & $89.0 \%$ & 1480 \\
\hline $\mathrm{Ar}-18 \% \mathrm{CO}_{2}-2 \% \mathrm{O}_{2}$ & 36.9 & $63.2 \%$ & $85.4 \%$ & 1415 \\
\hline Ar- $5 \% \mathrm{CO}_{2}-5 \% \mathrm{O}_{2}$ & 30.7 & $73.3 \%$ & $94.7 \%$ & 1502 \\
\hline $\mathrm{Ar}-12 \% \mathrm{CO}_{2}-4 \% \mathrm{O}_{2}$ & 27.5 & $82.1 \%$ & $96.0 \%$ & 1402 \\
\hline $\mathrm{Ar}-20 \% \mathrm{He}-12 \% \mathrm{CO}_{2}$ & 30.2 & $74.7 \%$ & $95.3 \%$ & 1546 \\
\hline $\mathrm{Ar}-30 \% \mathrm{He}-6 \% \mathrm{CO}_{2}$ & 29.2 & $76.8 \%$ & $93.3 \%$ & 1559 \\
\hline $\mathrm{Ar}-30 \% \mathrm{He}-10 \% \mathrm{CO}_{2}$ & 28.8 & $77.7 \%$ & $95.5 \%$ & 1547 \\
\hline $100 \% \mathrm{CO}_{2}(32 \mathrm{~V})$ & 25.8 & $79.9 \%$ & $89.5 \%$ & 1509 \\
\hline
\end{tabular}

6 revealed that $\mathrm{Ar}-5 \% \mathrm{O}_{2}$ had a greater fraction of fume in the $0-20 \mathrm{~nm}$ range.

The ternary mixtures of $\mathrm{Ar}-\mathrm{CO}_{2}-\mathrm{O}_{2}$ are split in to 3 categories, 1) increasing $\mathrm{CO}_{2}$ with $\left.2 \% \mathrm{O}_{2}, 2\right) 5 \% \mathrm{CO}_{2}$ with increasing $\mathrm{O}_{2}$ and 3) $12 \% \mathrm{CO}_{2}$ w ith increasing $\mathrm{O}_{2}$. Category 1 showed a similar trend to the binary $\mathrm{Ar}-\mathrm{CO}_{2}$ mixtures, where the particle size increased with increasing $\mathrm{CO}_{2}$ and the addition of $2 \%$ oxygen further enhanced the coarsening of particles. Increasing the oxygen addition further (categories 2 and 3), resulted in a slight increase in average particle size at $5 \% \mathrm{CO}_{2}$ but a decrease for the $12 \% \mathrm{CO}_{2}$ group. Generally, particle size increased as reactive gas components, $\mathrm{O}_{2}$ and $\mathrm{CO}_{2}$, increased, with the notable exception for $\mathrm{Ar}-12 \% \mathrm{CO}_{2}-4 \% \mathrm{O}_{2}$.

The particle size distribution was closely related to the reactive gas content of the shielding mixtures. For both binary and ternary argon mixtures containing $\mathrm{CO}_{2}$ and $\mathrm{O}_{2}$, the particle size shifted to coarser average sizes as the reactive components of the shielding gas composition increased. Particle growth is driven by condensation and coagulation. In welding, both of these mechanisms are limited due to the rapid cooling rate of the vapour, about $10^{7} \mathrm{~K} \mathrm{~s}^{-1}$. ${ }^{11)}$ As a result of this, small particles can only be consumed by larger particles due to collisions, as time for competitive growth by solute diffusion is restricted. Collisions of liquid-liquid particles will combine to form a single, larger particle, while solid-solid particle collisions generally results in agglomeration. If solid particles collided and formed a single, larger particle it would be polycrystalline in nature. TEM observations revealed single crystal structures, typified by that shown to Fig. 4. From this it is concluded that the size distribution of welding aerosol for GMAW was determined from the temperature at which the particle nucleated. That is, the range of supercooling.

Fume is generated by the nucleation and condensation mechanism. According to classical nucleation theory, the critical diameter of a nucleus is inversely dependant on the degree of supercooling. ${ }^{11)}$ The further the vapour is transported away from the high temperature arc zone, by the plasma jet, the lower the temperature of nucleation and the smaller the particle. Conversely, the earlier the initiation of nucleation of the vapour the higher will the temperature be and the coarser the particle. Results indicate that increasing the $\mathrm{CO}_{2}$ and $\mathrm{O}_{2}$ in Ar-based shielding gas promotes early initiation of nucleation as indicated by the observed increase in average particle size. It is proposed that higher additions of $\mathrm{CO}_{2}$ and $\mathrm{O}_{2}$ provide increased concentration of ionised oxygen in the vicinity of the metal vapour, increasing the driving force for nucleation of metal oxides. Zimmer noted a similar result where it was observed that an increase in $\mathrm{CO}_{2}$ concentration in the shielding gas significantly increased the particle number concentration of diameters $<20 \mathrm{~nm}$ in collected welding aerosols. Furthermore, the addition of oxygen to shielding gases can increase the heat input into the droplet due to constriction of the arc plasma. An increase in temperature is likely to promote coarser particles.

The notable exception, to the trend discussed above, was the ternary $\mathrm{Ar}-12 \% \mathrm{CO}_{2}-4 \% \mathrm{O}_{2}$ composition, where increasing the oxygen level decreased the particle size in comparison to the $\mathrm{Ar}-12 \% \mathrm{CO}_{2}-2 \% \mathrm{O}_{2}$ mixture. This result may be explained by a change in the oxidation mechanism from iron oxides nucleating in the gaseous phase to oxidation of the liquid iron on the droplet surface. The latter is favoured by higher reactive gas partial pressure (around 10\%). ${ }^{21)}$ Turkdogan's oxidation enhanced evaporation model for steelmaking fumes ${ }^{22,23)}$ showed that once oxygen pressure exceeded a critical value, enabling a continuous liquid oxide layer to form on the surface of molten iron, the fume formation would practically cease. Due to the complex and extreme conditions in a welding arc, it would be unlikely that a continuous liquid oxide layer could be maintained, as indicated by a significant amount of fume still generated with $\mathrm{Ar}-12 \% \mathrm{CO}_{2}-4 \% \mathrm{O}_{2}$ shielding gas. It is suggested that if a liquid oxide layer even briefly formed on the droplet surface, fume formation would be retarded, favouring the generation of finer particles at lower temperature.

The $\mathrm{Ar}-\mathrm{He}-\mathrm{CO}_{2}$ group showed near identical particle size distribution curves (Fig. 8) and all three shielding gas compositions had an average particle size of approximately $30 \mathrm{~nm}$. There was no indication that changing the $\mathrm{He}$ or the $\mathrm{CO}_{2}$ level influenced the particle size distribution for the selected compositions.

The normalised frequency versus particle diameter plot for the $100 \% \mathrm{CO}_{2}$ shielding gas is presented in Fig. 9 for $32 \mathrm{~V}, 34 \mathrm{~V}$ and $36 \mathrm{~V}$. The particle size coarsened with increasing voltage and most notably there was a significant drop in the $0-20 \mathrm{~nm}$ size group. Raising the arc voltage increases the arc temperature and the length of the arc promoting increased vaporisation, which increases the amount of fume generated. Results also indicate that raising the arc voltage promotes coarser fume particles.

The average size was misleading for the $100 \% \mathrm{CO}_{2}$ tests, for example, the average particle size at $32 \mathrm{~V}$ was smaller than all the Ar-based shielding gases, but a significantly long tail of coarse particles was recorded in Fig. 9. The exceptionally large proportion of $0-20 \mathrm{~nm}$ particles signifi- 


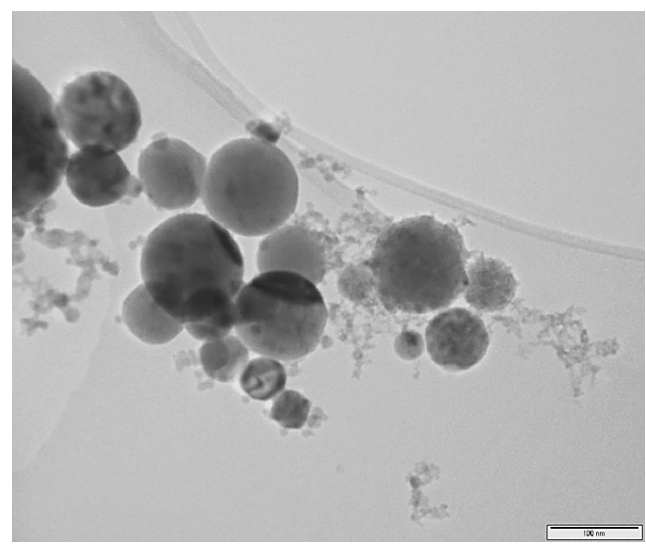

Fig. 11. Bright-field TEM image at $200 \mathrm{Kx}$ showing a range of coarse particles mixed with groups of very fine particles $(100 \mathrm{~nm})$.

cantly skewed the average particle size to lower values. It is not likely that the large proportion of particles $<20 \mathrm{~nm}$ would be due solely to $100 \% \mathrm{CO}_{2}$ shielding gas providing increased oxygen for nucleation because of the change of welding transfer to globular. A change from spray transfer to globular would be expected to significantly alter the fume generation characteristics.

The TEM analysis revealed two distinct groups of particles, a wide range of spherical particles from approximately 20 to $120 \mathrm{~nm}$ and clusters of groups of fine particles all below $20 \mathrm{~nm}$, typical of that shown in Fig. 11. TEM analysis indicated that many of these clusters were Iron oxide as opposed to $(\mathrm{Fe}, \mathrm{Mn})_{3} \mathrm{O}_{4}$. It was first speculated that these fine clusters were an artefact, washed-off the spatter particles during ultrasonic cleaning. To check this, spatter particles were collected on aluminium SEM stubs, carefully removed and placed in the ultrasonic cleaner in a bath of ethanol. The particle contaminated ethanol was then dropped onto TEM grids as before. A small number of fine, spherical fume particles were observed (some fume would have deposited on the spatter during collection), but not the fine clusters (typical of that shown in Fig. 11). Therefore the change in particle distribution, in comparison with the Arbased shielding gases, was attributed to the change in metal transfer from spray to globular. Fine clusters of particles may result when the arc is briefly extinguished, causing a sudden drop in temperature and a 'burst' in nucleation of extremely fine particles.

\subsection{Fume Composition}

The combination of TEM-EDS with XRD reveals that $\mathrm{Fe}_{3} \mathrm{O}_{4}$ was the dominant phase. The uniform, crystalline nature of the fume particles (Fig. 3) and the detection of $\mathrm{Mn}$ and $\mathrm{Si}$ in all particles indicates that fume particles are $(\mathrm{Fe}, \mathrm{Mn})_{3} \mathrm{O}_{4}$ with trace $\mathrm{Si}$ additions.

The TEM-EDS results in Table 2 showed a wide range of scatter for the analysis of particles for different shielding gas compositions; no discernable trend was observed. This suggests that shielding gas has no discernable effect on particle composition. The exception was a noticeable increase in the Si level when welding with $100 \% \mathrm{CO}_{2}$ shielding gas.

Grouping TEM-EDS results into particle size ranges, $<20 \mathrm{~nm}, 21-40 \mathrm{~nm}, 41-60 \mathrm{~nm}, 61-80 \mathrm{~nm}$ and $>81 \mathrm{~nm}$ re- vealed a slight variation of composition with particle size range, as shown in Table 3 and Fig. 2. Silicon was the only element to show significant change, where Si increased as particle size decreased. Due to the relatively low vapour pressure of $\mathrm{Si}$ it could be expected that $\mathrm{Si}$ would nucleate first resulting in higher Si compositions for newly nucleated particles. It appears that the increase in Si resulted in a corresponding decrease in $\mathrm{Fe}$ as particle size decreased. Overall, the variation of particle composition was minor.

The variation of composition with particle size is an important parameter in determining fume toxicology because particles of different sizes have different characteristics when inhaled. ${ }^{19)}$ Manganese is an element of interest and results showed that $\mathrm{Mn}$ had negligible variation with particle size therefore bulk fume composition would be an acceptable way to report Mn levels.

The average ratio of $\mathrm{Mn}$ to $\mathrm{Fe}$ in the reported fume particles in Table 2 was 0.088 . This is higher than that of the welding wire (0.012). This enrichment of $\mathrm{Mn}$ in the fume is likely to be a result of the relatively high partial pressure of Mn at welding arc temperatures. ${ }^{5)}$

\section{Conclusions}

The influence of shielding gas composition on particle size distribution and composition of aerosols generated by robotic GMAW on mild steel plates has been investigated. TEM analysis revealed that the majority of fume particles were spherical, single crystals and below $100 \mathrm{~nm}$ in diameter. The average particle size increased as the reactive components $\left(\mathrm{O}_{2}\right.$ and $\left.\mathrm{CO}_{2}\right)$ of the shielding gas increased, with the exception of $\mathrm{Ar}-12 \% \mathrm{CO}_{2}-4 \% \mathrm{O}_{2}$. This was explained by the increase in $\mathrm{O}_{2}$ and $\mathrm{CO}_{2}$ promoting a higher driving force for nucleation. A higher driving force would promote nucleation at higher temperature, which would be more favourable for the formation of coarser particles. Increasing $\mathrm{He}$ or $\mathrm{CO}_{2}$ in ternary $\mathrm{Ar}-\mathrm{He}-\mathrm{CO}_{2}$ mixtures had little impact on the particle size distribution. TEM observations showed fume particles were a mixture of spherical and faceted morphology.

Shielding gas composition had little influence on particle composition and fume particles were identified as $(\mathrm{Fe}, \mathrm{Mn})_{3} \mathrm{O}_{4}$ with trace additions of $\mathrm{Si}$. Fume composition showed only slight variation with particle size, where Si increased as particle size decreased.

\section{Acknowledgement}

Linde-BOC Gases, Australia is gratefully acknowledged for the funding and support for this project.

\section{REFERENCES}

1) H. R. Castner: Weld. J., 74 (1995), 59.

2) P. J. Hewitt: Indoor Built Environ., 5 (1996), 253.

3) V. Voitkevich: Welding Fumes: Formation, Properties and Biological Effects, Abington Publishing, Cambridge, England, (1995).

4) P. J. Hewitt and A. A. Hirst: An. Occ. Hyg., 35 (1991), 223.

5) R. F. Heile and D. C. Hill: Weld. J., 54 (1975), 201.

6) Y. Jin: Staub-Reinhalt. Luft, 54 (1994), 67.

7) Z. Sterjovski, J. Brossier, E. de Thoisy, D. Cuiuri, J. Norrish and B. Monaghan: Aust. Weld. J., 51 (2006), 34.

8) M. Kobayashi, S. Maki, Y. Hashimoto and T. Suga: Weld. J., 62 (1983), 190. 
9) A. T. Zimmer: J. Environ. Mon., 4 (2002), 628.

10) Standards, AS2985 (Standards Australia, 2004).

11) N. T. Jenkins and T. W. Eagar: JOM, 55 (2003), 44.

12) S. K. Friedlander: Smoke, Dust and Haze: Fundamentals of Aerosol Behavior, John Wiley \& Sons, New York, (1977).

13) I. Pires, L. Quintino and R. M. Miranda: Mater. Des., 28 (2007) 1623.

14) I. Pires, L. Quintino, R. M. Miranda and J. F. P. Gomes: Toxicol. Environ. Chem., 88 (2006) 385.

15) J. W. Sowards: Weld. World, 50 (2006), 40.

16) A. T. Zimmer, P. A. Baron and P. Biswas: J. Aerosol Sci., 33 (2002), 519 .
17) A. T. Zimmer and P. Biswas: J. Aerosol Sci., 32 (2001), 993.

18) S. Zhou, J. Norrish and Z. Chen: Proc. of Materials 98, The Biennial Conf. of the Inst. of Materials Eng., ed. by M. Ferry, (1998), 295.

19) N. T. Jenkins and T. W. Eagar: Weld. J., 84 (2005), 87.

20) P. Konarski, I. Iwanejko and M. Cwil: Vacuum, 70 (2003), 385.

21) I. Ioffe, D. MacLean, N. Perelman, I. Stares and M. Thornton: J. Phys. D, Appl. Phys., 28 (1995), 2473.

22) E. T. Turkdogan, P. Grieveson and L. S. Darken: J. Phys. Chem., 67 (1963), 1647.

23) E. T. Turkdogan and L. E. Leake: J. Iron Steel Inst., (1959), June, 162 . 